\title{
Energy Performance and Improvement Potentials for Selected Heritage Building Adaptation in England
}

\author{
O. K. Akande ${ }^{1 *}$, D. Odeleye ${ }^{1}$, A. Coday ${ }^{1}$ and C. Jimenez Bescos ${ }^{1}$ \\ ${ }^{1}$ Department of Engineering and Built Environment, Anglia Ruskin University, Chelmsford, \\ United Kingdom.
}

Authors' contributions

This work was carried out in collaboration between the authors. Author OKA designed and conducted the study, performed the analysis, wrote the protocol and the draft of the manuscript. Authors DO, AC and CJB assisted in the study design, supervised the analyses, reviewed the draft of the manuscript and helped with the revisions. All authors read and approved the final manuscript.

Article Information

DOI: 10.9734/BJECC/2015/19791

Original Research Article

Received $27^{\text {th }}$ June 2015

Accepted $23^{\text {rd }}$ July 2015

Published $2^{\text {nd }}$ August 2015

\begin{abstract}
Public heritage buildings (PHBs) were evaluated with the aim to determine their operational energy performance and the objectives of identifying improvement potentials for their long term sustainable reuse. Six listed churches initially used for worship and later converted to community uses were selected and surveyed as case study buildings using purposive sampling technique. A qualitative analytical approach based on ranking the performance of the surveyed building's energy consumption assessment compared to others within the same geographical region was adopted. Findings show that a greater number of the surveyed buildings are low-performing with their energy use being exacerbated by the combination and interplay of multiple factors such as building use pattern, efficiency of services and lighting etc. Results of the findings imply that potential and identifiable prospects for efficiency improvements and $\mathrm{CO}_{2}$ emissions reduction exists within the operation of the buildings. Recommended actions for wide-scale improvements in the form of capital replacement, retrofit/refurbishment, behavioural and improved operational management and control were suggested. The study concluded wider opportunities towards achieving energy saving such as energy management programme, building energy refurbishment scheme and use of energy efficient equipment could enhance stainable reuse of PHBs.
\end{abstract}

Keywords: Energy performance; public heritage buildings; sustainability; conservation. 


\section{INTRODUCTION}

Climate change has become an important driver for changing the way in which the built environment is produced and managed. This has led to increasing pressure for the existing building stock including heritage buildings to incorporate measures to reduce its $\mathrm{CO}_{2}$ emissions. However, heritage buildings pose special problems where compromises may be needed between maintaining the integrity of the original structure and adapting them to climate change. An example of the challenges from heritage buildings is a section of part $L$ of the building regulations which excludes listed buildings and those in conservation areas. Essentially, achieving holistic sustainable management of heritage buildings requires all aspects of sustainable development to be taken from the perspective that aims to satisfy the present needs without compromising the opportunities for satisfying the needs of the future generations.

In the UK, traditionally constructed buildings is defined by English Heritage as mostly all buildings constructed before 1919, in addition to a significant proportion of those built prior to 1945 with solid walls constructed of moisturepermeable materials [1-2]. Sometimes these buildings are referred to as 'historic', 'conservation buildings', 'older properties' or 'heritage buildings'. It is noteworthy that current refurbishment work involving existing buildings has a central part to play in meeting the UK's long-term emissions reduction goals. This could reach beyond the minimum standards of building regulations. By adopting the best possible practice standards wherever this is technically, functionally and economically feasible, can lead to achieving a remarkable improvement in the levels of energy performance.

The environmental sustainability of existing buildings has raised a lot of concern within the scientific community. Despite the advocate of several researchers [3-6] on the importance of focusing on incorporating green and sustainable environmental design and features into reuse of existing heritage buildings; yet there is little evidence in literature focusing on how environmental sustainability of these buildings can be improved. This significant gap in knowledge is most pronounced with heritage buildings in public use. Furthermore, other researchers [7-9] have also emphasized that energy efficient refurbishment of existing buildings is an essential tool for reducing energy use in the building sector. However, in many refurbishment and conversion of heritage buildings, this is yet to be fully achieved in practice.

\section{ENERGY PERFORMANCE AND HERITAGE BUILDINGS}

Poel et al. [10] described energy performance of a building as the amount of energy actually consumed or estimated to meet the different needs associated with a standardised use of the building. This is reflected in one or more numeric indicators calculated while considering parameters (e.g. insulation, technical and installation characteristics, design and positioning in relation to climatic aspects, solar exposure and influence of neighbouring structures, building's own energy production and other factors such as indoor climate) that affect the energy demand. Currently, methods adopted for investigating energy performance of heritage buildings have concentrated on investigating their U-value either to prove or disprove their energy efficiency or inefficiency. Whilst this has resulted to perceived tension between the design professionals, the planning and conservation officers and researchers when considering energy efficient retrofit to heritage buildings [11]. On the other hand, non-invasive methods, modernisation and energy reduction strategies compatible with conservation projects such as those involving energy management approaches for improvement in environmental sustainability of heritage buildings are yet to be fully explored.

For instance, strategic design concepts specific with remodelling and conversion of heritage buildings with potentials to reduce energy consumption exists and yet to be fully explored. Robert [12] describes the concepts such as building within or pod insertion as outstanding examples of architectural conversions. This innovative design concept is a non-invasive technique of enclosing relatively smaller space needed and heating such space without heating the entire volume of space. Consequently, this reduces the amount of energy required to heat the entire space most especially in buildings with large volume of space such as churches. English Heritage [13] has also suggested several strategies that could benefit traditional building retrofit from the greatest energy savings at lowest risk of damage and decay to the building. Such strategies include draught proofing of windows and doors, roof insulation, replacement 
of outdated services with high efficiency units, upgraded controls, floor insulation and possible installation of secondary glazing. Other possible areas that could be explored to minimize energy consumption in reuse projects is the consideration of renewable sources of energy.

Although the predicted impact of intrusive systems is usually influenced by conservation purposes and most times discourage designers. However, other systems such as biomass and ground source heat pumps though subject to availability, storage or costs are less disruptive and could also be given consideration. More importantly, if energy saving approach from good housekeeping resulting from user's behaviour is encouraged; and more awareness and motivation for energy use reduction created, this could have stronger influence on changing users behaviour and actions. One of the ways this could be carried out is by constantly providing energy use feedback to the users through automatic meters capable of giving visual information on progress against targets. Moreover, with the current recognition and importance attached by the government to the use of smart meters, energy consumers could be well furnished with real data upon which to assess their actions and operational practices. Adequate information from metering has the potential to yield energy savings up to 3 to $15 \%$. However, this could only be possible if the building operators routinely review the information obtained so as to reveal undetected energy waste. Thus, providing the opportunity to make changes in the way the building is operated. Additionally, regular inspection, constant control settings and time-switches, ensuring efficiency of plant and equipment could result to reduction in energy wastage and improve the performance of the building.

In the UK, among the common methods for assessing energy performance of a building is the Standard Assessment Procedure (SAP). The SAP method determine the heating systems fuel efficiency and the building fabric thermal efficiency on a scale from 1-100 [11]. Drawing conclusions from the assessment obtained from the use of SAP method; in 2006, the government data indicate that older properties have poor energy performance. Most especially, emphasis was laid on over $40 \%$ of properties built prior to 1919 showing SAP ratings of less than 41 compared with $60 \%$ of those built from 1990s upwards having SAP ratings of over 70 [14]. However, the use of SAP has been vigorously challenged by several authors [15-18] arguing that SAP and other methodologies such as Reduced data Standard Assessment Procedure (RdSAP), Energy Performance Certificates (EPCs) and National Home Energy Rating (NHER) generates widely varying results with faulty underlining assumptions for the predictions of older buildings. The authors [15-18] argued that this software and the accompanying methodologies are characterised by inbuilt inflexibility and their generic treatments predispose older buildings to less accurate energy efficiency ratings.

Moran et al. [19] stated that in spite of government statistics showing higher $\mathrm{CO}_{2}$ emissions from the historic buildings, there are still differences in how their energy efficiency is perceived. These differences emanate from more research that has been geared towards investigating and modelling the thermal and energy use performance of heritage buildings. For instance, literature indicates two main methods could be used to determine the baseline performance of the building envelope. This could either be laboratory-based or in-situ based method and measurements. However, the limitation of the laboratory-based method is the inability in real settings to capture the complexities of hygrothermal properties and perhaps other behaviours of building materials [20]. This is especially the case with pre-1919 buildings and its traditional materials in which inaccurate data on the variety of materials used and their properties reduces the certainty of their baseline U-values not based on in- situ measurements.

According to the outcome of research conducted by $[15,17,21,22]$ using in-situ measurement, traditional building materials appears to perform better than expected. This implies the possibilities that the performance of walls built of traditional building materials (i.e. solid walls) is underestimated when other methods (i.e. the laboratory and calculation method) set out in the British Standard are used. This view is supported by Rye and Scott [22] who stated that the actual construction of the traditional element and other unknown properties (i.e. defective areas, irregularities, etc.) along with other characteristics of local materials could lead to localised thermal performance variations and discrepancies between calculated and in situ thermal performance. Thus, evidence from the findings of these authors show that the differences in the perception of energy 
performance of heritage buildings has led to conflicting claims on their energy efficiency. This has rather been regarded as either good [23-25] or poor $[14,26,27]$.

\subsection{Investigations on Energy Performance of Heritage Buildings}

English Heritage [1] accepts that measures to increase energy efficiency of heritage buildings can be incorporated without significant damage to the buildings. With this acceptance came the development of various guidelines to 'balance the needs of energy conservation with those of building conservation' as required by Part $L$ of the building regulations. The regulations seek to improve the energy performance of all buildings, new and old, when they are altered, extended or subjected to change of use [1] and made provision for the improvement of energy efficiency in heritage buildings provided their heritage significance is not jeopardised. This is in agreement line with the view of [1], [28-30], Cambridge Centre for Sustainable Development [31] survey of UK-based future developments and pathways advocating that improvement in the performance of the existing building stock is crucial to achieving the required reductions [32]; [13]. Thus, leading to other studies regarding measures undertaken to reduce carbon emissions from heritage buildings sector.

A study of older buildings by Department for Communities and Local Government [14] has shown that a substantial reduction in carbon emissions can be made by introducing cost effective technology which can make substantial savings on fuel bills for consumers. However, the study did not go beyond finding a correlation between building age and poor energy performance. The findings show pre-1919 buildings as the worst performing of all the categories of the existing building stock. Meanwhile, no clarifications from the findings about the possibilities of other factors that might have impacted on energy consumption of these buildings. Hence, this result has been criticized by a number of authors $[33,16,19]$ arguing that the method of using the Standard Assessment Procedure (SAP) model to derive the findings is capable of providing inaccurate assessment of the energy performance of traditional buildings.

Wallsgrove [23] considers the energy efficiency of law courts in the UK and reported conflicting results to the findings of [14]. He identifies pre1900 buildings to be the most energy efficient with 1940-1960 buildings being 35-45 percent less efficient. While his findings are very instructive and revealing, however, they may not be applicable to all buildings within those periods. Furthermore, Wallsgrove [23] did not address the whole spectrum of factors and other variations that may be found in other types of buildings. Therefore, there is the need for further studies focusing on other public heritage buildings to validate the applicability of the existing findings to other buildings. It could be concluded from the above review that the current standard methods and data used to determine energy performance of traditional buildings may not be the optimal solutions to determine how their energy performance could be assessed in reality. This underscores the need for energy performance data taken from actual buildings to inform the debate and the practices relating to energy reduction strategies for heritage buildings. Thus, this study differs from the previous studies in the sense that it does not attempt to investigate the thermal performance of PHBs and compare them with modern buildings. Rather, a different approach was adopted to evaluate energy performance and improvement potentials to current energy performance of existing PHBs.

\subsection{Energy use Intensity for Energy Performance Assessment of Heritage Buildings}

A critical review of the range of energy efficiency indicators is given by Patterson [34] in determining energy consumed in a facility. However, the most common, non-invasive and non-intrusive suitable to heritage buildings is the energy metric that break down energy use by floor area called energy use intensity (EUI). According to Kamaruzzaman and Edwards [35], the energy use per unit floor area is also described as 'Normalised Performance Indicators' (NPI). The use of EUI has the advantage of showing the way energy use is compared between various types of buildings and could also be used to evaluate the means of reducing overall energy consumption. Ueno [36] described floor-area-normalised EUI to be excellent for assessing the energy-use performance of non-domestic building because of the advantage it has to be less affected by climate. Some researchers such as Birtles and Grigg [37] Singapore e-Energy Benchmark System [38] have adopted the use of EUI to assess the energy performance in many buildings. Other instances of using EUI include 
Filippin [39] who used the sample of energy consumption data and floor area to determine the EUI for school buildings in central Argentina and ranked the result obtained on a benchmark table.

Although some authors such as Kissock et al. [40] argued that the energy consumption of buildings could adequately and better be determined by using parameterized models that relate energy consumption to outside temperature. However, according to Ueno [36] the limitations of this method is that it cannot capture the complexities and realities of the actual building. Other critics [41] and [42] of the use of EUI have also argued that other factors (e.g. HVAC system) could perhaps lead to either higher or lower energy consumption in specific buildings than those observed among their peers. However, in spite of the controversies regarding the use of EUI, there is no question about the value it can bring to aid the understanding and analysis of building energy performance. Thus, Ueno [36] argued that the estimation of EUI from energy bills and comparing it to values obtained for similar buildings is useful for comparison as it examine real numbers as opposed to models versus models, and/or models versus reality.

The aim of this study is to assess the operational energy performance of selected PHBs converted to community uses. The objective is to evaluate the improvement potentials specifically with regards to their sustainable reuse. Thus, the cause of high energy consumption in the lowestperforming buildings could be appropriately diagnosed and lessons could be learned from the high performing buildings. Such information would be useful in providing adequate understanding of how their energy use could be conserved and effectively managed. Foliente and
Tucker [43] opines that actual in-use performance is important as the outcomes and significance is actual while it also helps to confirm design or refurbishment goal which could contribute to the knowledge to improve future practice. In this paper, the concept of performance is investigated from the view of actual in-service performance (during occupancy) of existing reuse of PHBs. The rationale is to establish their actual operational performance and its impact on the environment.

\section{RESEARCH STRATEGY AND APPROACHES}

\subsection{Building Eligibility}

The determination of the building eligibility for the survey was undertaken in a two-step process. The first step was undertaken during the development of the sample while the second step was carried out during the interview with the building managers. Redundant (i.e. closed) churches of England converted to community uses was selected as case study buildings surveyed for this research. The rationale behind the selection of churches includes the following:

- They constitute over a third (1/3) of all grade I listed buildings in the UK [44]

- The largest have been estimated to have carbon emissions tens of times those of a typical family home [45]

- They cover a broader spectrum and are found in every community

- About 1,696 churches from 1969-2010 had been declared redundant while 1,033 have been converted to other uses between 1969-2010 [46].

Table 1. Building activity/function and annual energy use of surveyed buildings

\begin{tabular}{|c|c|c|c|c|c|}
\hline $\begin{array}{l}\text { Building } \\
\text { code }\end{array}$ & Main use & Secondary use & $\begin{array}{l}\text { Floor } \\
\text { area }\left(m^{2}\right)\end{array}$ & $\begin{array}{l}\text { Energy use } \\
\left(\mathrm{kWh} / \mathrm{m}^{2}\right)\end{array}$ & $\begin{array}{l}\text { Type of energy use } \\
\text { (Electricity/ Gas/ } \\
\text { Electricity \&Gas) }\end{array}$ \\
\hline B6 & Music school & Music school & 327 & 16 & Electricity \\
\hline B5 & $\begin{array}{l}\text { Cultural Performance } \\
\text { and dance }\end{array}$ & $\begin{array}{l}\text { Cultural Performance } \\
\text { and dance }\end{array}$ & 262 & 48 & Electricity \\
\hline B2 & Educational art & Educational art & 173 & 195 & Electricity and gas \\
\hline B1 & Theatre & $\begin{array}{l}\text { Cultural performance \& } \\
\text { Music concert }\end{array}$ & 429 & 366 & Electricity and gas \\
\hline B4 & Musical concerts & $\begin{array}{l}\text { Theatre, cultural } \\
\text { performance \& dance }\end{array}$ & 201 & 510 & Electricity and gas \\
\hline B3 & Musical concerts & $\begin{array}{l}\text { Art studio, Photography } \\
\& \text { Theatre }\end{array}$ & 228 & 1263 & Electricity and gas \\
\hline
\end{tabular}


Since the majority of English churches are listed buildings, churches can potentially make a huge contribution to tackling climate change especially when they are considered for reuse. Thus, to be eligible for the survey, two major criteria were considered. Firstly, the building had to meet the location criteria (i.e. East of England); secondly, it had to have its uses converted for community purposes. East of England was selected based on the following characteristics:

- Has third largest in number of listed buildings in the UK

- Comprises of over 2,300 places of worship (Norfolk alone having over 700)

- Has the highest number of reuse of churches for community use

- Has good representative mix of Grade I, II* and II reuse projects

Using a purposive sampling of potential building cases within the geographical region, six converted churches to community uses in the urban areas were sampled and selected for this study. Buildings in the urban areas where selected as that is where the demand for community uses is far greater than the rural areas. Based on the arguments of Saunders et al. [47] there are no rules for sample size in nonprobability sampling, rather, the actual size depends on available resources and the logic behind the sample selection. Thus, the above sampling approach was considered appropriate for the research.

\subsection{Data Collection}

Field surveys were conducted to assess the energy performance characteristics in the reuse of PHBs in East of England. The survey consisted of site observation, meeting with the operation managers to collect as much information about the buildings as possible and collecting energy bills/invoice for a 12-month period. The survey was implemented in the six buildings from the period of March - June 2013. Data was collected by the researcher using a self-developed questionnaire instrument through a face to face technique. The information requested in the questionnaire include: building features, size, age, year of conversion, use patterns (i.e. operating hours, number of workers, number of visitors), energy-using equipment (i.e. heating, cooling, refrigeration, lighting and office equipment), energy management practices, types of energy use and its uses, energy generation, and expenses on energy use for operating the building. Energy performance of the surveyed buildings was evaluated using a method adopted from Saidur [48] estimation of energy use intensity (EUI) in $\mathrm{kWh} / \mathrm{m}^{2}$ from the following equation:

$$
E I=A E C / T F A
$$

Where, $\mathrm{AEC}=$ annual energy consumption (kWh)

TFA is total floor area $\left(\mathrm{m}^{2}\right)$

EUI is indicated in this study by $\mathrm{kWh} / \mathrm{m}^{2} /$ year after [49]-[50]. It should be noted that the results of the findings are deliberately reported primarily on qualitative basis due to the sample size $(\mathrm{n}=$ 6) and qualitative approach adopted for the study.

\subsection{Study Buildings/Area}

A summary of key building features is shown in Table 1. The building varies in sizes with a total gross floor area ranging from $173 \mathrm{~m}^{2}-429 \mathrm{~m}^{2}$. The buildings were classified according to their sizes. The small size buildings were classified as buildings up to $250 \mathrm{~m}^{2}$. The larger size buildings were classified as buildings ranging from 250$450 \mathrm{~m}^{2}$. Most of the buildings were built between $14^{\text {th }}-19^{\text {th }}$ centuries and were mainly medieval in architectural style. The buildings surveyed were churches converted to arts and entertainment use classified according to their main use above (Table 1). The main use of the buildings is educational training in arts and music, theatre and music concerts.

\section{RESULTS AND DISCUSSION}

\subsection{Comparison with Benchmarks}

Benchmarking serves as an important initiative in the drive for energy efficiency improvement and a mandatory requirement of the European Union (EU) Directive on Energy Performance of Buildings. It is a method of comparing a building's utility consumption with typical or best practice figures. Benchmarking was employed in this study to assess the standard of energy efficiency of the surveyed buildings in order to enable remedial action to be taken. Table 2 shows the benchmarks taken from CIBSE TM46 [51]. The benchmark covers public buildings with light use that include churches as they are considered to be public buildings according to CIBSE guidelines. Although churches are not 
categorised by type, age, size or construction according to these guidelines, it was necessary to use this as only a rough comparator. This was important as the energy benchmarks have been derived from distributions of metric values obtained from facilities having similar characteristics. In addition, benchmarking allow the researcher to compare the energy consumption level of one building with another within the same group and at the same time help to identify measures to reduce their energy consumption [52].

Fig. 1 shows the comparison between the benchmark and annual energy consumption for the buildings surveyed. It is interesting to note that building 'B6' use less energy than the expected benchmarked annual utility consumption. It could be observed that although building 'B5' appears to have low energy consumption, its annual energy usage is more than twice compared to the benchmarked annual utility consumption. It is worth nothing that the energy consumption of the remaining buildings (i.e. B2, B1, B4, and B3) was considerably higher than the benchmarked utility consumption. For instance, it could be seen that the annual energy use of building 'B2' is nearly twice compared to the benchmark; while that of building 'B1' is more than twice, building 'B4' and 'B3' is four times and ten times higher compared to the benchmark. This shows the need to assess the operational use and practices and other possible factors that may be responsible for the lowperforming buildings compared to the high performing ones.

Table 2. Annual utility benchmarking

\begin{tabular}{llll}
\hline & Benchmarks & Units & $\begin{array}{l}\text { Benchmarked } \\
\text { annual utility } \\
\text { consumption }\end{array}$ \\
\hline Gas & $105 \mathrm{kWh} / \mathrm{m} 2$ & $390 \mathrm{~m} 2$ & $40,950 \mathrm{kWh}$ \\
Electricity & $20 \mathrm{kWh} / \mathrm{m} 2$ & $390 \mathrm{~m} 2$ & $7,800 \mathrm{kWh}$ \\
\hline \multicolumn{2}{c}{ Source:CIBSE TM 46:2008 Energy Benchmarks }
\end{tabular}

\subsection{Energy Performance Indicator}

In order to determine the energy performance indicator of the surveyed buildings, energy consumption data collected from the buildings was converted into $\mathrm{kg}$ of $\mathrm{CO}_{2}$ emission using DEFRA [53] $\mathrm{CO}_{2}$ emission conversion factors. The collected data was converted to the equivalent $\mathrm{CO}_{2}$ emission factors using the conversion factor of $0.184 \mathrm{~kg}$ of $\mathrm{CO}_{2} / \mathrm{kWh}$ for gas and $0.542 \mathrm{~kg}$ of $\mathrm{CO}_{2} / \mathrm{kWh}$ for electricity. For the purpose of this research, the equivalent carbon emissions from the buildings is reported in 'relative' terms giving the absolute figure indexed to a unit of per $\mathrm{m}^{2}$ per performance which can also be referred to as 'intensity indicators'. The energy performance indicator (EPI) for the investigated buildings is depicted in Table 3.

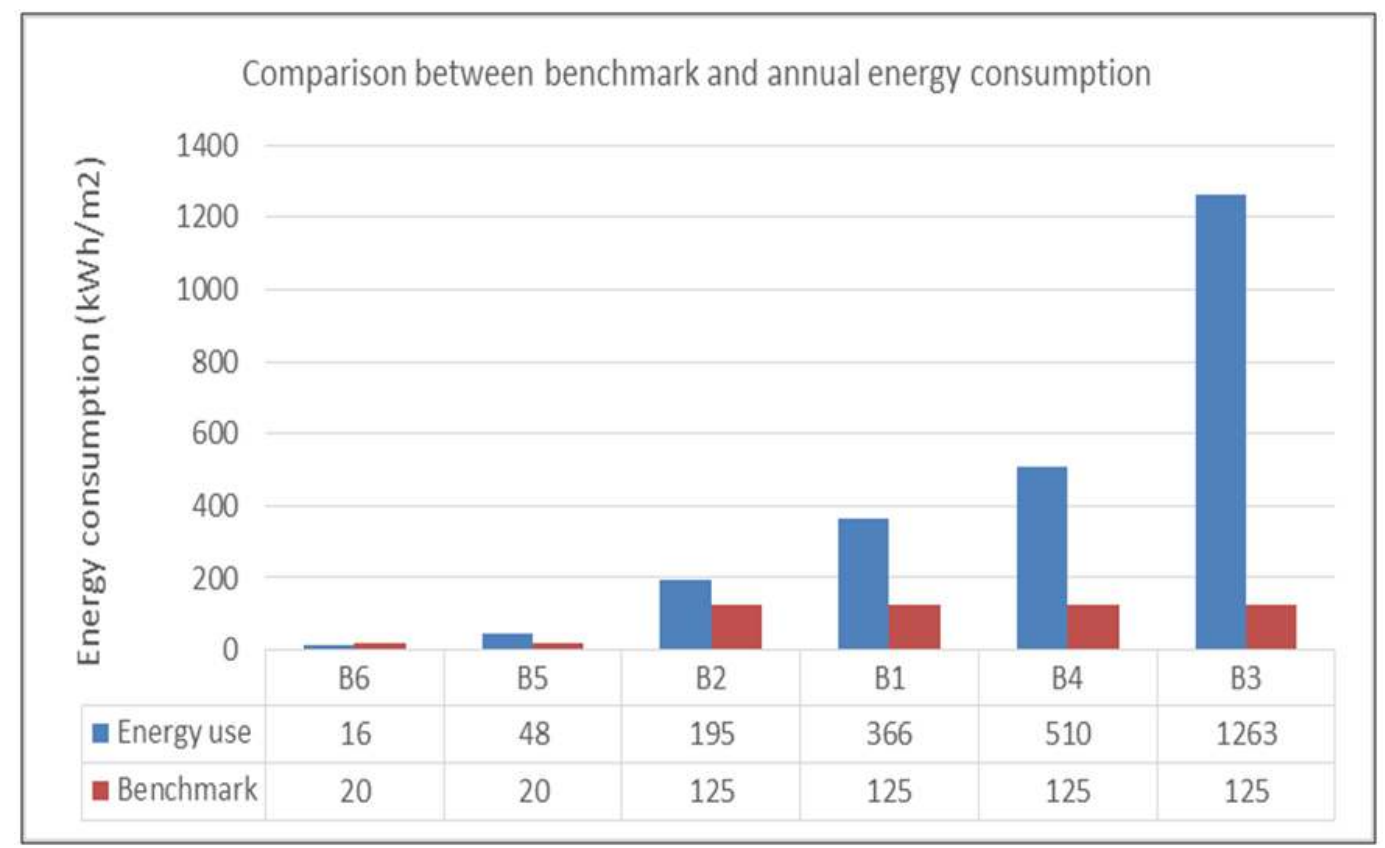

Fig. 1. Comparison between benchmark and annual energy consumption 
Table 3. Building energy performance of surveyed buildings by ranking

\begin{tabular}{|c|c|c|c|c|c|c|c|}
\hline \multirow[t]{2}{*}{$\begin{array}{l}\text { Building use } \\
\text { type }\end{array}$} & \multicolumn{3}{|c|}{ Building characteristics } & \multicolumn{2}{|c|}{ Energy performance indicator } & \multicolumn{2}{|c|}{$\begin{array}{c}\text { Performance } \\
\text { ranking }\end{array}$} \\
\hline & $\begin{array}{l}\text { Building } \\
\text { code }\end{array}$ & $\begin{array}{l}\text { Year } \\
\text { built }\end{array}$ & $\begin{array}{l}\text { Grade } \\
\text { listing }\end{array}$ & $\begin{array}{l}\text { Energy use } \\
\left(\mathrm{kWh} / \mathrm{m}^{2}\right)\end{array}$ & $\begin{array}{l}\mathrm{CO}_{2} \text { Emissions } \\
\left(\mathrm{kgCO}_{2} / \mathrm{m}^{2}\right)\end{array}$ & High/Low & Rank \\
\hline Arts and & B6 & C15 & I & 16 & 9 & High & 1 \\
\hline Entertainment & B5 & C14 & i & 48 & 26 & High & 2 \\
\hline use & B2 & C14 & i & 195 & 47 & Low & 3 \\
\hline & B1 & C15 & 1 & 366 & 57 & Low & 4 \\
\hline & B4 & C19 & ॥ & 510 & 199 & Low & 5 \\
\hline & B3 & $\mathrm{C} 14$ & i & 1263 & 364 & Low & 6 \\
\hline
\end{tabular}

It can be seen that the total annual energy use per heated floor area ranges from 16 $\mathrm{kWh} / \mathrm{m}^{2} /$ year to $1263 \mathrm{kWh} / \mathrm{m}^{2} /$ year with a mean of $399.67 \mathrm{kWh} / \mathrm{m}^{2} /$ year. Building 'B6' was found to have a low EPI of $16 \mathrm{kWh} / \mathrm{m}^{2}$ with the lowest $\mathrm{CO}_{2}$ emissions $\left(9 \mathrm{kgCO} / \mathrm{m}^{2}\right)$ indicating best energy performance. On the other hand, it could be observed that building 'B3' have the highest $\mathrm{EPI}$ of $1263 \mathrm{kWh} / \mathrm{m}^{2} / \mathrm{year}$ with the highest $\mathrm{CO}_{2}$ emissions $\left(364 \mathrm{kgCO} / \mathrm{m}^{2}\right)$ indicating the poorest energy performance. To facilitate a comparison between the buildings, energy performance indicator for individual building activity and function were ranked according to their performance (1=High performance, $6=$ low performance). The purpose of the ranking is to enable comparison to be made with similar buildings size and similar pattern of use in order to be adequately informed of the actions to be taken to improve the energy performance of the low-performing buildings. It can be seen that buildings 'B6' (educational art/music) and 'B5' (cultural performance/dance) ranked 1st and 2nd as the only high performing buildings with low energy use of $16 \mathrm{kWh} / \mathrm{m}^{2}(0.7 \%)$ and $48 \mathrm{kWh} / \mathrm{m}^{2}$ $(2 \%)$ respectively.

It could be observed that building ' $\mathrm{B} 2$ ' (educational art/music) has smaller floor area $\left(173 \mathrm{~m}^{2}\right)$ and ranked $3 \mathrm{rd}$ with higher energy use of $195 \mathrm{kWh} / \mathrm{m}^{2}(8.3 \%)$ much higher than its counterparts ' $\mathrm{B} 6$ ' $\left(327 \mathrm{~m}^{2}\right)$ with the same building activity and function. Building 'B1' used for theatre is ranked 4th with energy use of 366 $\mathrm{kWh} / \mathrm{m}^{2}$ (15.3\%). Meanwhile, buildings 'B4' and 'B3' both used for musical concerts ranked 5th and 6th as the highest energy consuming building function with energy use of $510 \mathrm{kWh} / \mathrm{m}^{2}$ $(21.3 \%)$ and $1263 \mathrm{kWh} / \mathrm{m}^{2}(53 \%)$ respectively. By comparison, building 'B6' and 'B5' exceptional performance could partly be explained in relation to their single use activity as both main and secondary use of the internal space compared to other buildings having multiple uses. Other reasons could be attributed to the fact that the buildings only use electrical energy as the only source of energy. From the comparison between buildings (B6, B5, and B2) with single use activity, it can be seen that as the building size decreases, energy consumption increases. This is rather surprising as it can be seen that building 'B2' appears to be the smallest in size in their category and contrary to expectation and common knowledge that the smaller the building size, the less energy would be consumed.

Further observation showed that 'B2' used more than twice the energy when compared to CISBE benchmarked for energy use. This high energy consumption could be due to other reasons such as space heating requirements and the intensity of energy use. Most especially for lighting and cooling as the field survey indicate that the building is used for various cultural performance. Other possible explanations could be as result of frequency of use and increased number of people using the building weekly, especially at night which would require more use of energy consuming lighting facilities such as flood lighting, more energy generating activities that may also require the use of other electricity generating equipment such as sound system typically use in theatre and cultural centre. Thus, based on the pattern of usage, it is expected that energy consumption for 'B2' will be much higher when compared to building 'B6' whose main activity is just limited to musical training. A further comparison revealed that the smaller size buildings are put to more uses when compared to larger ones. This indicates there is more preference for the use of smaller size buildings. This perhaps could also have been as a result of the perception that smaller buildings are easier to manage and affordable to operate. Thus, the preference for smaller buildings could have possibly resulted in more frequent usage which leads to high energy consumption.

The differences observed in the energy performance of the surveyed buildings could also 
be as a result of dual and/or multiple usage of some of the buildings (B1, B3 and B4). As it can be seen that the energy use data obtained from these buildings are remarkably high compared to other buildings and the CISBE benchmarked for energy use. Further investigation into the cause of high energy use by the buildings reveals the use lots of energy end uses such as process plant (e.g. refrigeration, freezers) and other energy-intensive appliances (e.g. use of catering appliance such as cookers oven etc.). High energy consumption in the buildings is also perceived to have resulted from other multiple factors arising from negative user's behaviour towards energy consumption and poor efficiency of the building heating systems etc. Thus, leading to large variation in energy use among the investigated buildings. In addition, building 'B5' have an extension facilities which accommodated more community uses. It could be argued that the extension facilities might possibly have more frequent use than the actual heritage building which perhaps might have also resulted in more energy use by the entire building.

Interestingly, findings from this study revealed that heritage buildings could perform better than what their performance is perceived to be compared to their modern buildings counterparts. This is evident in the high performance of buildings 'B6,' and 'B5' built prior to 19th centuries. This findings thus agree with the findings of Wallsgrove [23] whose findings on energy efficiency of law courts in the UK identified pre-1900 buildings to be the most energy-efficient when compared with post 1900 buildings such as 1940-1960 which were found to be $35-45$ percent less energy efficient. This negate the myth that all older buildings are less energy efficient. Although, on the contrary, it was also observed that other low-performing buildings ('B2', 'B3' and 'B4') were also built between 14th15th centuries. This findings thus shows that other unknown factors (e.g. such as use pattern, type, age and efficiency of services and lighting, use of equipment, users' behaviour etc.) could result to significant energy consumption in the surveyed buildings.

\section{SUGGESTIONS AND RECOMMENDA- TIONS FOR POTENTIAL IMPROVE- MENTS}

The findings from this study suggest that significant opportunities and improvement potentials exists which could be harnessed to reduce energy consumption in the reuse of PHBs. These are categorised into four namely: capital replacement actions, retrofit/ refurbishment actions, behavioural actions and improved operational management and control. The improvements from capital replacement actions include lighting replacement with LED systems of all energy consuming lighting systems such as halogen lighting; energy consuming appliances and equipment (e.g. refrigeration, cooker, etc.) greater than 10 years old with best available technology. The typical effectiveness of halogen lighting is 17 lumens per watt, compared to at least 50 lumens per watt for LED lights. Therefore, if all halogen lights were to be replaced by LED lighting, estimate shows that total energy consumption could be reduced by two-thirds equating to huge savings in energy and substantial reduction in $\mathrm{CO}_{2}$ emissions per annum. Similarly, process plant (e.g. refrigeration etc.) could account for almost two-thirds of energy consumption in a medium size food service retailers. Thus, the potential energy savings for process plant should be based on replacing equipment greater than 10 years old. Furthermore, reducing energy consumption through improved management and control would require optimisation of control for key energy-using equipment, introducing a system to monitor energy consumption, providing training for staff and setting targets for energy consumption reduction.

Additionally, the impact of negative user behaviour as it affects energy consumption would also need to be addressed with adequate and effective control mechanisms and measures put in place. This could be in the form of placing information labels as a reminder in conspicuous places, giving regular feedback on monthly energy use, instruction on simple energy saving techniques etc. These measures could perhaps check and reduce negative user's behaviour which eventually could contribute to the energy use reduction. Furthermore, tenants/occupiers could be made responsible for their energy consumption while using the building by paying their energy bills according to their usage. This could serve as a motivator for tenant/occupiers' energy savings as well as serve as effective means of ensuring good housekeeping and regulating user' behaviour. However, if the energy bills are only included in the rent as it is the current practice, and the tenants are unaware of the cost of their energy consumption on the building owner and the environment, this could further encourage bad housekeeping and 
consequently increase their energy use. In addition, operation managers would also need to set targets for proactive action to ensure energy use reduction annually for instance up to an average of not less than $5 \%$ per year. This could also result in a huge saving of annual energy consumption as well as reducing yearly $\mathrm{CO}_{2}$ emissions.

There is need for all organisations (i.e. tenants) using heritage buildings to establish an energy management role to manage energy use in their operations. Whilst operational approach to managing energy use could vary considerably with different organisations, it is recommended to have a separate individual or a team of staff to manage energy and the building. The implication of this is that energy consumption resulting from energy using products (e.g. refrigeration, lighting, equipment etc.) could be managed by a different individual or team from energy use influenced by the building fabric (e.g. such as insulation levels). On the other hand, the appointment of either the operation manager or assistant manager should partly be based on an individual with background in energy management training; with the role of dealing with all energy related matters as well as providing advice on energy management.

\section{IMPLICATION FOR PRACTICE}

It is hoped that this study would contribute to improving the decision involving energy refurbishment and/or designing reuse of existing PHBs, adoption of appropriate strategies and technologies in reuse of $\mathrm{PHB}$ projects and avoidance of costly interventions with negative impact on heritage building's values. The knowledge of current operational energy performance of $\mathrm{PHB}$ projects could benefit the owners, facility (operation) managers and tenants in identifying areas where operational energy savings could be made to more effectively manage energy use of their buildings. This would enable them to compare the energy performance of their building within the same building portfolio and geographical region as well as become informed on the actions to be taken to boost the performance of their buildings. Finally, the result of this study could serve as valuable information that can be used at a decision point when leasing, buying or financing reuse of listed churches or similar PHBs.

\section{CONCLUSION}

This study presented the findings on energy performance in six converted listed church buildings converted to arts and entertainment uses in East of England. High-energy consumption was identified in four out of the six buildings surveyed for the study. Surprisingly, it was found that energy consumption could be observed to vary considerably and continuously plateaued with decrease in size of the buildings in some of the cases. One of the undisputed findings of this study is that the range of energy performance of the buildings is dramatic. While there were buildings at the high-performance level, the majority of the buildings were in the low-performance level. It is noteworthy, that energy use was found to be exacerbated by combination and interplay of several factors such as building use pattern, type, age and efficiency of services and lighting.

Although, due to the regular use of reuse of $\mathrm{PHBs}$ and the consequent change in the energy use pattern; approaches adopted to achieving energy efficiency in modern buildings could also be implemented in these buildings. Nevertheless, due to the peculiarity of heritage buildings and statutory regulation surrounding their protection, careful measures need to be taken into consideration in adopting such approaches such as wall insulation. However, other measures such as reduced lighting power, efficient building systems (i.e. efficient boilers and occupancy sensors), appliances, equipment, positive behavioral actions, improved operational management and control has been identified as improvement potentials for PHBs. In conclusion, the measures indicated in the study should take priority in heritage building energy refurbishment scheme and more importantly attention should be given to energy management programme and installation of energy efficient equipment to enhance the sustainable reuse of PHBs.

\section{ACKNOWLEDGEMENTS}

The research study described in this paper was undertaken as part of a Doctorate research project on "Energy Management in Reuse of Public Heritage Buildings" funded by the Department of Engineering and the Built Environment, Faculty of Science and Technology, Anglia Ruskin University, Chelmsford, United Kingdom.

\section{COMPETING INTERESTS}

Authors have declared that no competing interests exist. 


\section{REFERENCES}

1. English Heritage. Building Regulations and Historic Buildings - Balancing the needs for energy conservation with those of building conservation: An Interim Guidance Note on the application of Part L. 2004;2004. Available:http://www.englishheritage.org.uk /upload/pdf/ign partl buildingregs.pdf

2. English Heritage. Heritage Counts 2010: England; 2010a.

Available:http://hc.englishheritage.org.uk/c ontent/pub/HC-Eng-2010 [Accessed 28 July 2011]

3. Snyder GH. Sustainability through Adaptive Reuse: The Conversion of Industrial Building. Master University of Cincinnati; 2005.

4. UNEP. Buildings and Climate Change: Summary for Decision-Makers. ed.: UNEP Publications; 2009.

5. Langston C. Green adaptive reuse: Issues and strategies for the built environment. Paper presented to first international conference on sustainable construction and risk management Chong Quing Municipality, China. 2010;12-14.

6. Getty Conservation Institute. Sustainability and heritage in a world of change, professionals forum held at Getty Centre. $2011 ; 11$

Available:http://www.getty.ed/conservation/ public programs/sustain.html

7. Gorgolewski M. Optimizing renovation strategies for energy conservation in housing, Building and Environment, 1995; 30(4):583-589.

8. Papadopoulos AM, Theodosiou ThG, Karatzas KD. Feasibility of energy saving renovation measures in urban buildings. The impact of energy prices and acceptable payback time criterion, Energy and Buildings. 2002;34(5):455-466.

9. Hong $\mathrm{SH}$, Oreszczyn T, Ridley I. The impact of energy efficient refurbishment on the space heating fuel consumption in English dwellings, Energy and Buildings. 2006;38(10):1171-1181. Issue in Stoke on Trent. Journal of Property Research. 19(2): 93-110.

10. Poel B, Cruchten GV, Balara CA. Energy Performance Assessment of Existing Dwellings. Energy and Buildings. 2007; 39(4):393-403.

11. Friedman $\mathrm{K}$, Cooke $\mathrm{A}$. Is UK Planning a barrier to energy efficient retrofit: A comparative analysis of a selection of
London Boroughs. Retrofit Conference, University of Salford; 2012.

Available:http://www.salford.ac.uk/ data/a ssets/pdf file/0008/142379/016-

Friedman.pdf

12. Robert $\mathrm{P}$, Adaptations. New Uses for Old Buildings. Editions du Moniteur: Paris; 1989.

13. English Heritage. Efficiency and Historic Buildings. Application of Part $L$ of building regulation to historic and traditionally constructed buildings. London; 2012a.

14. DCLG. A Decent Home: Definition and guidance for implementation, DCLG Publications; 2006.

15. Rye C. The SPAB Research Report 1: The U-value Report. Revised 2011. London: The Society for the Protection of Ancient Buildings; 2010.

16. Rye C. The energy profiles of historic buildings: A comparison of the in situ and calculated U-values of traditionally built walls, Unpublished MSc Dissertation University of Portsmouth, UK; 2011.

17. Baker P. Technical Paper 10-U-values and Traditional Buildings, Edinburgh: Historic Scotland; 2011.

18. CITB (Council and Industry Training Board), English Heritage.Performance and Energy Efficiency of Traditional Buildings: Gap Analysis Study; 2012.

Available:http://www.sdfoundation.org.uk/d ownloads/STBA-Gap-Analysis-StudyPerformance-and-Energy-Efficiency-ofTraditional-Buildings-Final-Version-(2).pdf

19. Moran F, Nikolopoulou M, Natarajan S. Developing a database of energy use of historic dwellings in Bath, UK; 2012. Available:http://www.salford.ac.uk/energy/r esearch/retrofit-conference/retrofit-2012papers-day-2

20. BRE (Building Research Establishment). Solid wall heat losses and the potential for energy saving-Literature review. BRE Report; 2014.

21. Rye C, Hubbard D. The performance of traditional buildings: The SPAB building performance survey 2011- Interim findings. In Proceedings of Retrofit 2012 conference, University of Salford, Manchester; 2012.

22. Rye C, Scott C. The SPAB research report. U-value report. First published 2010, revised November. Report for the Society for the Protection of Ancient Buildings; 2012. 
23. Wallsgrove J. Cutting down on Carbon: Improving the Energy Efficiency of Historic Buildings, Gheu Seminar at Bre, Garston energy Usage in Older Buildings; 2008.

24. English Heritage. Hearth and Home: Energy efficiency research; 2009.

25. Wood C. Making historic building even more sustainable. Institute of Historic Building Conservation (IHBC) Context. 2009;111;39-41.

Available:http://ihbc.org.uk/context archive /111/wood/CTX111.html.

26. EHCS English House Condition Survey. Full Report; 2007.

Available:http://environment/climatechange luk/ukccp/pdf/ukccp06-all.pdf

27. Boardman B. Examining the carbon agenda via the $40 \%$ House scenario, Building Research and Information. 2007; 35:(4):363-378.

28. Foresight. Powering our Lives: Sustainable Energy Management and the Built Environment, London, the Government Office for Science; 2008.

29. Mackay DJC. Sustainable Energy- Without the Hot Air, Cambridge, UIT; 2009.

30. DECC (Department of Energy and Climate Change). 2050 Pathways Analysis. London: Department of Energy and Climate Change; 2010a.

31. Cambridge Centre for Sustainable Development. Scenarios for the Future of Energy Management in Buildings and Property Developments. Cambridge: University of Cambridge; 2011.

32. DTI (Department of Trade and Industry). Energy White Paper Our Energy Future Creating a Low Carbon Economy. London; 2003.

33. Heath N, Pearson G, Barnham B, Atkins R. Technical paper 8-energy modelling of the garden bothy, Dumfries house. Edinburgh: Historic Scotland; 2010.

34. Patterson MG. What is energy efficiency? Concepts, indicators and methodological issues. Energy Policy. 1996;24(5):377-90.

35. Kamaruzzaman SN, Edwards RE. Evaluating performance characteristics of electricity use of British historic building in Malaysia, Facilities. 2006;24:141-152.

36. Ueno K. Building energy performance metrics. Building Science Digest. 2010; 152.
37. Birtles AB, Grigg P. Energy efficiency of buildings: Simple appraisal method. Build Serv Eng Res Technol. 1997;18(2):109-14.

38. E-Energy Benchmark System. National University of Singapore and the Building and Construction Authority of Singapore, Singapore; 2003.

Available:http://www.bdg.nus.edu.sg/builde nergy/e-energy/commercial.html

39. Fillippin C. Bench marking the energy efficiency and greenhouse-gasses emissions of school buildings in central. Argentina. Build Environ. 2000;35:407-14

40. Kissock JK, Haberl JS, Claridge DE, Inverse Modelling Toolkit: Numerical Algorithms. Ashrae; 2003.

41. Monts JK, Blisset M. Assessing energy efficiency and energy-conservation potential among commercial buildings: A statistical approach. Energy. 1982;7(10): 861-9

42. Sharp T. Energy benchmarking in commercial-office buildings. In ACEE 1996 summer study on energy efficiency in buildings. 1996;4:321-9.

43. Foliente GC, Tucker SN. Performance setting and measurement for sustainable commercial buildings; 2004.

44. The Church Heritage Forum. A Future For Church Buildings. A report from the Church Heritage Forum; 2003.

45. Eco congregation; 2006.

Available:http://ew.ecocongregation.org/do wnloads/Encraft.pdf

46. Church Commissioners Annual Report. The Church Commissioners for England; 2010.

Available:https://www.churchofengland.org /media/1244828/final\%20annual\%20report \%20at\%2019\%20april\%202011.pdf

47. Saunder $M$, Thornhill $A$, Lewis $P$. Research methods for business student, $1^{\text {st }}$ edition, Pitman, London; 2009.

48. Saidur R, Energy consumption, energy saving, and emission analysis in Malaysian office buildings, Energy Policy. 2009;37: 4104-4113.

49. Ibrahim $\mathrm{H}$. Best practices and innovation of buildings in Malaysia, Paper presented at Seminar on The Promotion on Energy Efficiency and Conservation for Building in Southeast Asia, Singapore; 2008.

50. Chou SK. Performance-based standards for energy efficiency building, Paper 
presented at Seminar on Building Control (Amendment), Singapore; 2004.

51. CIBSE, (Chartered Institution of Building Services Engineers). Energy Benchmarks: CIBSE TM46. CIBSE, London; 2008.

52. CIBSE, Energy Efficiency in Buildings, CIBSE Guide F, 2nd edition, Chartered
Institution of Building Services Engineers (CIBSE), London; 2004.

53. DEFRA (Department for Environment Food and Rural Affairs). E-Digest of Statistics; 2009.

Available:http://www.defra.gov.uk/environ ment/statistics/globatmos/gakf07.htm

(C) 2015 Akande et al.; This is an Open Access article distributed under the terms of the Creative Commons Attribution License (http://creativecommons.org/licenses/by/4.0), which permits unrestricted use, distribution, and reproduction in any medium, provided the original work is properly cited. 